\title{
Correspondencia entre la postura onto-epistemológica y teleológica del investigador y su método de investigación en el patrimonio
}

\author{
CORRESPONDENCE BETWEEN RESEARCHER ONTO-EPISTEMOLOGICAL AND TELEOLOGICAL \\ APPROACH AND HIS METHOD OF RESEARCH IN HERITAGE
}

\begin{abstract}
Dra. Alejandra Ojeda (aojedasampson@gmail.com) Universidad Latina de México (Guanajuato, México)
Dr. Marco Sifuentes (rgbrulio@yahoo.com.mx) Universidad Autónoma de Aguascalientes (Aguascalientes, México)
\end{abstract}

\begin{abstract}
The aim is to show that study objects that address social problems (whether architectural, cultural or heritage, among others, but with emphasis on the subjectivity, perception, and the habitat of actors), should be analysed with a consistent method to it complexity, i.e. critical dialectical, because it not only explains the problem, but transforms the current conditions with the intention of enhancing its constituent elements. The first section shows the onto-epistemological and teleological assumptions of the study object, the second the explanation of an epistemic matrix that displays the location of the problem, thus establishing the right process for its approach.
\end{abstract}

Keywords: dialectical, critical, appropriation, identity, totality, heritage.

\section{Resumen}

Se trata de mostrar que los objetos de estudio que aborden problemas sociales (sean estos arquitectónicos, culturales o patrimoniales, entre otros, pero con énfasis en la subjetividad, percepción y el propio habitar de los actores), deben ser analizados con un método consecuente a la complejidad del mismo, siendo éste la dialéctica-crítica, puesto que no se trata solamente de explicar el problema, sino de transformar las condiciones existentes con una intencionalidad potenciadora de los elementos que lo constituyen. Para ello se recurre, en un primer momento, a la explicación de los supuestos ontoepistemológicos y teleológicos del objeto de estudio, y en un segundo momento, a la explicación de una matriz epistémica que permite visualizar la ubicación del problema, estableciendo en consecuencia, el proceso adecuado para su abordaje.

Palabras clave: dialéctica, crítica, apropiación, identidad, totalidad, patrimonio. 


\section{Introducción}

El objetivo principal de este artículo es mostrar, primero, la postura onto-epistemológica y teleológica del investigador en la observación de su objeto de investigación y, segundo, señalar el método investigativo para llevar de manera congruente y pertinente esa postura epistémica. De esa manera se inicia el discurso enfatizando que la complejidad de la vida obliga a observarla desde la totalidad de la misma, mostrándose ésta interactuante en sí y para con los elementos que la constituyen. Por ello, cualquier reflexión, análisis o propuesta que se plantee sobre cualquiera de sus componentes, debe ser abordado desde un paradigma que permita esta necesidad epistémica.

Para la explicación de la construcción cognitiva hasta ahora realizada, la estructura del artículo se plantea con base en dos grandes apartados sustantivos: los supuestos onto-epistemológicos y el método. Dentro del primero, se revisan tres grandes categorías de análisis: el hombre, el espacio y el patrimonio. En cada apartado, donde su denominación representa en sí misma una categoría de análisis, aparecerán visiblemente expresadas tales categorías que permitan comprender el entramado categórico-conceptual en el que se apoya la investigación en curso. En el segundo apartado, denominado el método, se explican brevemente las distintas maneras de abordar una investigación social, mostrando finalmente la pertinente a las necesidades onto-epistémicas del objeto de estudio.

\section{Supuestos onto-epistemológicos}

En este apartado deberá entenderse por supuestos onto-epistemológicos al entramado categóricoconceptual que permite comprender la postura que del ser que se tenga, así como la misma en cuanto a la aprehensión de éste.

\subsection{El hombre}

Para la comprensión de cualquier evento o fenómeno social, particularmente si de arquitectura se refiere, es necesario comenzar por el análisis y discusión sobre la génesis del hombre. Múltiples y diversas han sido las concepciones que se poseen de él. Una de ellas es la que construye Castoriadis. Este autor integra ónticamente las categorías de espacio y tiempo, al plantear que "el ser no está simplemente 'en' el tiempo, sino que es por el tiempo (mediante el tiempo, en virtud del tiempo). Esencialmente el ser es tiempo" (2005:64). En tanto Marc Augé señala al espacio como condición del individuo al enfatizar que el lugar de nacimiento será factor de constitución de la identidad individual. Luego, la condición del individuo no se podrá pensar sin el espacio y tiempo vivido, es decir, es cualidad óntica del mismo.

Por esa condición de movimiento, que el tiempo en el espacio construye, se puede constituir la alteridad del sujeto. Un individuo es en cuanto es diferente de los otros y por ello nombrado diferente para la confirmación de su identidad y de la ipseidad de estos. En este sentido, el cuerpo del hombre como materialización de él, resulta ser la forma del ser-uno-mismo en tanto manifestación del ser-en-situación dada. Por ello Ábalos dice: "El presente es el lugar en el que se dan las experiencias cotidianas; el 'hoy, ahora y aquí' desatendido por tantas otras formas de pensamiento" (2001:177). Vigotsky por su parte, y para explicar este estar-siendo del individuo, recupera la categoría de apropiación como mecanismo básico para el desarrollo humano, pues por medio de ella se 'apropia' del todo del hombre, para constituir su 'realidad'. Luego, el hombre no es un sujeto constituido universalmente, sino es el sujeto devenido y deviniente, capaz de construirse y reconstruirse continuamente. 
En ese construirse tiempo-espacio, el hombre se constituye a sí mismo con la capacidad de voluntad, como volitivo es el movimiento de realidad y los actos de ésta. El hombre no es sino en la medida que piensa y pensar presupone la posibilidad de actividad deliberada, por lo tanto de elección, como bien señala Castoriadis. El individuo, por ello, puede dirigir sus pensamientos y representaciones hacia ciertos objetos y no hacia otros. Y es por esta cualidad óntica que puede transformar el tiempo y el espacio vivido hacia otros pensados como posibilidad teleológica. El cambio y la recurrencia, entonces, son el sentido y esencia del ser vivo: el hombre es ser-siendo en el movimiento de la vida.

El espacio particular en el que se mueve y constituye el ser humano es la Tierra, por ello Arendt la señala como la quintaesencia de la condición humana, siendo así que Covarrubias menciona que la naturaleza Tierra- incluye al hombre, dado que éste es una especie más que, como todos los seres vivos, interactúa con ellos y con los seres abióticos. Postura dialéctica que piensa al hombre como la concreción de naturaleza y sociedad y no como lo sostiene el dualismo cartesiano de hombre separado de los 'otros' no humanos. En este sentido, Morin plantea a todo sistema físico como un dasein, un ser allí dependiente de su entorno y sometido al tiempo. Y como hombre actuante en el sistema físico, es plenamente un ser del tiempo y en el tiempo. Y entonces surge la apropiación del espacio como forma en que el individuo se haga a sí mismo en un contexto espacio-tiempo particular. En este sentido, es mediante esta apropiación que el hombre se constituye como persona. He aquí la importancia de que el sujeto humano se 'pare' en la tierra con la Tierra; significa la posibilidad de su humanización. Y en ese continuum háptico del ser, el cuerpo del sujeto le recuerda quién es y en qué posición se encuentra en el mundo cotidianamente vivido.

En esa particularidad de estar en el mundo, el sujeto construye el hábitat y con ello su habitar, siendo por ello instituyente del sujeto que le ha dado sentido, permitiéndole además arraigarse al sitio, como ya señalaba Marx. Y si bien el sujeto es en tanto que es sistema, es decir, sociedad, todo grupo humano asentado sobre un territorio adopta una estructura social. Por ello el espacio, en tanto que es vivido por el hombre, transita a lugar, es decir, a posibilidad de realización como individuo. Y en ese lugar particular se establecen lazos culturales y costumbres, definiendo por ello un lugar respecto a otro cotidianamente vivido por otros hombres iguales en su condición óntica, pero distintos en su historicidad. En este contexto particular, también se particulariza la condición lingual, es decir, se construye un contexto discursivo, resultando por ello que la experiencia no es anterior a la interpretación.

Esa construcción discursiva permite, entre otras cosas, la posibilidad de apropiación del sujeto con su lugar y con su grupo de inserción, entendiendo que ésta dependerá de los modelos culturales, roles sociales, formas y estilos de vida, así como de la imagen que se haya construido de sí mismo el individuo. Todo esto subyacente en el particular discurso construido en ese tiempo-espacio vivido en la cotidianidad. Entonces, el ser con los otros, es una condición dialéctica del sujeto individual en tanto sujeto social, que construye el lenguaje necesario para la apropiación del espacio que por esta condición deviene en lugar. Por ello Palau dice que "humanidad y sociedad existen sólo cuando se establecen relaciones de significación y procesos de comunicación" (2002:22).

El hombre si bien es individuo como tal, se constituye como ser humano en tanto nace en medio de cierta comunidad de interpretación que lo provee de un mundo instituido (e instituyente) de significado. Entonces para entender cualquier hecho humano, es necesario entender que éste ha sido construido por un sujeto colectivo con una determinada estructura mental significativa y coherente para ese grupo social, pero condensado de manera particular por el individuo. Gracias a esas construcciones mentales y esquemas de vida que el individuo construye, es posible formarse su mundo por lo que habrá múltiples mundos pertenecientes a distintos individuos, incluso pertenecientes al mismo grupo social. Sin embargo 
y si bien esos mapas son únicos, estos participan de elementos que los vuelven comunes, es decir, los sujetos tendrán en sus mapas cognitivos elementos significantes que les darán los soportes necesarios para sentirse pertenecientes a ese grupo social y a ese lugar en particular. Esa es la identidad. Entonces, dice Norberg-Schulz, los mundos formados son productos de motivaciones y experiencias del individuo en un sitio particular.

En ese sentido, para Zohn la identidad es una categoría que muestra una condición de movimiento en el sujeto, porque tanto éste como su espacio participan de la cualidad espacio-tiempo instituidos e instituyéndose. La apropiación del espacio, entonces, tendrá un carácter simbólico-expresivo e instrumental que permitirá, entre otras cosas, la conformación de la identidad del sujeto. Luego, que el individuo viva en un universo simbólico hará posible la constitución de ese sujeto en individuo, pues obtendrá las herramientas cognitivas-afectivas necesarias para sentirse perteneciente a ese lugar y grupo social, por lo tanto, miembro identitario con el mundo. En este sentido, las categorías de mundo simbólico, apropiación del espacio e identidad, formarán un nudo onto-gnoseológico en la constitución del ser humano.

En la constitución de ese sujeto, también se conforma su memoria. Ésta es el baúl afectivo-cognitivo en donde el individuo depositará su proceso constitutivo. La memoria representa el rescate de los recuerdos, en tanto construcción social, en un contexto de expresión de la tradición, siendo por ello un proceso eminentemente social. Sin embargo, esta memoria presente físicamente en los recuerdos expresados, no será una copia fiel de lo vivido por el sujeto: representará una reinterpretación de esos hechos por la reconstrucción de su universo simbólico que se encuentra en movimiento. En este sentido, la memoria remodela la experiencia vivida construyendo por ello 'mitos', como personajes ideales, lugares de añoranza o contra mitos como elementos de lo rechazable o de la exclusión. A la memoria se suma el recuerdo, que juntos constituirán un pasado construido en el presente con significados fundamentales para la identidad el sujeto que la posee. He ahí la importancia de la memoria, tanto para comprender al individuo, como a su espacio de existencia.

Se ha analizado la parte óntica del hombre. Es necesario ahora revisar también su proceso de comprensión, es decir, la episteme que lo vuelve posible. En este sentido, Castoriadis reflexiona sobre el sujeto y la sociedad que lo envuelve. Él denomina a este momento como la institución de las sociedades, señalando además que es un proceso particular y por ello fundamental en cada sujeto. En esta institución, cada grupo social lo hará a su manera, encontrándose por ello una dimensión diacrónica en este proceso y con esto la parte de la naturaleza en donde se inserta. Por ello es que el hombre es síntesis de naturaleza y sociedad, entendiendo que esto conduce a crear un conjunto de relaciones sociales que son al mismo tiempo relaciones con la naturaleza, pero no relaciones naturales. En este proceso de interacción, el hombre se apropia de su espacio transformándolo, por lo que existe también una producción societal. En este sentido, Íñiguez y Pol señalan que "la apropiación del espacio representa la propia imagen, simboliza a uno mismo, aunque la apropiación no consiste en la búsqueda intencional de una significación" (1996:11). 0 al menos no necesariamente.

Es así que para que la apropiación se construya e incluso se observe, debe haber una serie de signos que se han producido, no necesariamente en el momento de su manifestación, sino a lo largo de las generaciones. Estos signos también permiten la identidad del sujeto en su sentido de relación y de historia grupalmente compartida, observándose la dimensión diacrónica del sujeto y de la cultura construida. Entonces, en el sentido de lugar, Muntañola observa tres posibles orígenes en su significación: la polaridad habitar-hablar, la polaridad figurar-conceptualizar y la polaridad medio-físico/medio-social. Ante esto no 
es posible el análisis de ningún individuo o grupo social, que no obligue a una revisión onto-epistemológica de los mismos, pues su constitución es particular como específico es su movimiento.

Así como existen elementos constitutivos del ser humano como de la sociedad, es decir, supuestos ónticos de ellos, también es necesario observar que en esa constitución se encuentran categorías que la propia sociedad construye para la misma institución. Estos son los constructos sociales presentes en todo su quehacer, como lenguaje mítico-ritual, en el sentido de Bourdieu. De esta manera, categorías como modernidad, tradición e identidad, entre muchos más, son valores culturales, por lo tanto, constructos sociales que tendrán una contemporaneidad, dado el movimiento tiempo-espacio en el que se mueve esa sociedad. Es así, incluso, que hablar de patrimonio comprenderá unos valores, intencionalmente o no, construidos en cierto momento histórico. Sin embargo, si bien podría quedar claro que la apropiación comienza en un universo simbólico y discursivo con las palabras propias de una lengua particular, existe mayor dificultad en comprender que hay otras categorías que también son producto de esas construcciones sociales. La noción de espacio es un ejemplo nítido de ello. Ésta comporta no sólo lo espacial de 'cerca' y 'lejos', sino que en ella subyace una percepción de tiempo contenida en la noción de pasado, presente y futuro. La distancia, si bien es un vocablo para designar una longitud, en su trato social obedece a una intuición espacio-temporal. Este constructo implica entonces el de percepción. Categoría que debe tomarse como condición volitiva, pues percibir, como señala Norberg-Schulz, implica interpretar entre posibilidades intencionales. Entonces, se percibe estar cerca o lejos, próximo o distante, de acuerdo a las posibilidades intencionales que culturalmente se hayan construido.

Ahora bien, esa percepción no solamente se encuentra integrada por las construcciones sobre un pasado, sino que se instituye por expectativas y aspiraciones del sujeto percibiente. Por ello es que Marx señalaba que el acto de observar implicaba un acto de valorar, y valorará lo que históricamente se haya valorado. Entonces, percibir un hecho social, implicará tanto la valoración que realicen los sujetos externos a éste, como la de los nativos que lo viven. Dicho de otra manera, se observará un hecho social que históricamente pueda ser observado, pues contendrá las valoraciones culturales y los andamiajes categoriales para hacerlo. Y esto valdrá para todo aquello construido por el hombre, incluido por supuesto, el espacio que al recibir condición de existencialidad, devendrá lugar o territorio. Es así que un lugar significará valoraciones culturales construidas en un tiempo específico, mismas que pueden cambiar si las condiciones históricas se modifican, por ello entonces, lo que fuera un lugar podrá transitar a un solo espacio más.

Si bien esas observaciones se convierten en lecturas que realizan los propios moradores del espacio o los estudiosos de los mismos, éstas también significarán especificidades históricas. Para realizar una lectura, entonces, la herramienta para ello será la interpretación, permitiendo dar sentido a los diferentes elementos observados. De esta manera es necesario "realizar una lectura, por un lado, de las representaciones y prácticas en las que se construyen y se estabilizan los sentidos sociales y, por otro lado, de las necesidades y acciones cotidianas en las que se cristalizan" (Díaz, Grassi y Mainini 2011:1). Es decir, se trata de estudiar el espacio geográfico en cuanto espacio social devenido y deviniente, producto de la intervención humana y social sobre las leyes del medio físico definido y valorado por una comunidad instituida en un tiempo-espacio determinado. Sieglin por ello enfatiza que la 'mismidad' no es una propiedad de los objetos de estudio, sino que ésta es construida por el estudioso o el observador, entendiendo que éste también participará de esas construcciones axiológicas siendo por ello un proceso recursivo, no lineal. He aquí y en todo lo mostrado, el aspecto gnoseológico del hombre y de todo aquello que de él emane. 


\subsection{El espacio}

Si bien ya se ha abordado al espacio como categoría óntico-gnoseológica para comprender al hombre, es fundamental ahora analizarlo en sí mismo. Éste como parte esencial del desarrollo y ser del hombre, ha estado presente desde su conformación como tal, sin embargo, como motivo de reflexión, es con los griegos que adquiere importancia. Para comenzar, Aristóteles señala que existe porque existen cuerpos que lo definen. Es decir, para él y contrario a lo que pudiera decir Platón, es en la relación con otros elementos, y no en sí mismo, que puede ser percibido. Este planteamiento supone la existencia entonces de 'otros', y he aquí la enorme importancia para su comprensión y por supuesto, para el trabajo arquitectónico (que es el que nos ocupa), de y con él.

De entre esos 'otros' y como se ha venido mostrando, el tiempo es parte indisoluble de su existencia y lo que es más, para la existencia de la existencialidad del hombre. Ambos, espacio y tiempo, conforman un conjunto dialéctico en donde para la comprensión de uno debe incluirse al otro y viceversa. En este sentido, no existe historia anespacial, ni geografía atemporal. Incluso para Bourdieu, la percepción que cada persona construya de sí misma, tiene que ver con la posición que ocupe en el espacio; ese espaciotiempo históricamente determinado. Entonces, en esa ocupación del espacio y construcción de la persona, se establecerá una relación particular y específica entre ambos, que si ésta logra trascender para integrarse y conformar vivencias y huellas tanto en la persona que lo ocupa como en el espacio ocupado, se podrá hablar de apropiación del espacio. En esta relación dialéctica, la apropiación significará la transformación de ambos por encontrarse íntimamente interactuando.

Es así que se puede hablar de espacio solamente como una categoría de posición o referencia, pero lo que se trata de explicar, es que como tal no existe en la realidad, pues su existencia se debe a un constructo social que indica una valoración particular. El espacio del hombre (como categoría gnoseológica), implica una dimensión relacional, social, ambiental y particularmente emocional. Es decir, su percepción en la cotidianidad contempla aspectos objetivos que se han vuelto subjetivos y que tienen que ver con la propia historia de ese individuo que lo vive, por lo que su análisis debe considerar aspectos que permitan entender esos elementos que, además, como propio sujeto que se encuentra en un espacio, también vive.

Norberg-Schulz muestra al espacio arquitectónico (así lo refiere él), como aquel que materializa los esquemas ambientales o imágenes del hombre, incluso lo eleva al rango óntico-teleológico de ser, entre otros, el que permite al individuo el estar-en-el-mundo. Es así que el espacio comprende elementos que denotan aspectos con significados simbólicos mediados, dice Harvey, por procesos cognitivos. Y estos procesos corresponden a los construidos por la propia cultura de inserción del sujeto, como también a los correspondientes al desarrollo biológico del mismo. En este sentido, el espacio del hombre será concretizado y vivido de acuerdo a la edad del individuo en interacción con la construcción social que se haya instalado en el momento histórico vivido. Es en este punto donde ahora se habla de espacio habitable, instalando esta categoría de análisis que permite señalar de manera nítida la condición existencial del espacio del hombre.

Bachelard, coincidiendo con lo ya planteado, señala que el lugar es el espacio convertido en ser-siendo del hombre. Un lugar, por ello, sería la coexistencia entre el espacio y el tiempo, mediados por la acción del hombre en su devenir-deviniendo. Es por esto que Sala Llopart refiere que para que la sociedad convierta un simple espacio en lugar, el individuo debe hacerlo suyo, es decir, apropiárselo. Lo cual significará, entre otras cosas, un proceso simbólico, interaccional y volitivo. Esto muestra que la categoría de espacio no estaba explicando los distintos fenómenos que se observaban en el análisis del mismo y de la ciudad en su 
totalidad; era necesario construir o en su caso significar, una categoría que permitiera dar cuenta de lo que sucedía en los espacios actualmente ocupados por el hombre y la sociedad.

El lugar, con la categorización que se le está otorgando, se convierte en un elemento que muestra las características de ente vivo. Éste se mueve y plantea distintos 'argumentos', ya sea visto en los días, meses o años; su mensaje cambia conforme su sintaxis temporal se transforma. Al respecto señala García: "Los haceres de la vida diaria crean y articulan los lugares y dan movimiento a su interior, haciéndolo depositario de necesidades y deseos, de viejas y nuevas combinaciones entre el mundo exterior y los paradigmas axiológicos de los habitantes de la casa" (2004:68). Y si el lugar cambia conforme el habitante lo 'hace' cambiar, en cuanto él mismo cambia, entonces, la observación que de él se realice debe considerar de manera importante esta condición, pero más aún, debe considerar la propia condición de sujeto observador que cambia conforme es partícipe de esa sintaxis tempo-espacial. Muntañola al respecto señala que el lugar y la arquitectura muestran nítidamente la dialéctica entre la lógica del lugar y la experiencia que de éste se tenga.

Ahora bien, el lugar muestra esa porción de espacio en el que cotidianamente se mueve el hombre, sin embargo, el lugar mismo pertenece a otro espacio que le significa. Esto es el territorio. Merleau-Ponty diría que el lugar es ese algo perceptivo que se encuentra en el contexto de algo más, siendo ese más el campo de inserción o territorio. El territorio es el producto de un diálogo óptico-háptico entre el ser-siendo del hombre con y en la naturaleza. Es así que este contexto particular en que el individuo se inserta de manera específica, se conforma como una estructura simbólica sumamente compleja llegando ese individuo a determinar, por ello, el valor de cada roca, cada árbol o cada elemento biótico o abiótico. En este proceso de conformación del espacio en territorio, se observan distintos momentos, en palabras de Salazar: "a su vez entre el territorio etológico y social se pasa por el territorio psicológico y después del social por el territorio existencial y más allá, el simbólico" (2011:23). El territorio, entonces, se construye e instituye en la cotidianidad de distintos grupos de personas que interactúan de manera cercana y que además ellos mismos ya han significado su espacio como lugar. El territorio será, por lo tanto, la suma dialéctica de lugares.

Si bien el territorio es esa totalidad dialéctica de lugares, la territorialidad es la expresión de las relaciones sociales que se originaron y se construyen en él. La territorialidad es la manera en cómo las personas conforman redes sociales que les permiten definirse como tales. En este sentido, tratar de entender el territorio conllevará necesariamente analizar espacios que fueron existencialmente valorizados por haber sido culturalmente construidos, instituyéndose en este proceso dialéctico la territorialidad. El espacio posee una dimensión física, que al volverse significante por el sujeto que lo vive existencialmente deviene lugar. Así mismo, este lugar se encuentra inserto con otros lugares en un espacio más amplio, que al constituirse ambiental y dialécticamente significante, transita a territorio, reflejándose esta condición en la territorialidad. Toda una imbricación de espacio-tiempo del hombre en su devenir-deviniendo que, por ello mismo, adquieren complejidades específicas y diversas.

El hombre, como ya se mencionó, es la condensación de la sociedad a la que pertenece, como ésta es la totalidad de los sujetos que la condensan. En este proceso dialéctico se instituye la condición de polis, por lo que el ser humano se vuelve un ser político que participa de relaciones de dominio. En este sentido, las territorialidades, al contrario de las clases sociales, no son 'producidas' por los modos de producción, sino por un proceso de poder, de dominación social y política. Es así que en el territorio se dan cita esos dominios del hombre para el hombre, y de éste con su espacio. Sin embargo, en esa interacción puede 
construirse un dominio transformador de ambos o por el contrario, un dominio reduccionista de la condición de ser existencial.

El territorio y el lugar son los espacios del grupo social en el que se encuentra inserto el sujeto, la vivienda por el contrario, es el lugar de la unidad social más pequeña, pero quizás más importante de esa sociedad instituida, debe ser considerada como una parte de todo el sistema social y espacial, relacionándose aspectos de ella, el modo de vida, el asentamiento y el paisaje. Es así que la vivienda es el lugar de mediación en su interior con los miembros que la conforman, como con el exterior y con los miembros de los que la familia forma parte como grupo social. Todos ellos participantes de otros lugares y viviendas como mediadoras. Por esta condición, en ella se dan cita 'fragmentos identitarios' que el sujeto ha vivido en los otros espacios en su cotidiano vivir, llevando por ello las tensiones propias de estos. La vivienda en sí misma impone una concepción del sitio, de la sociedad y aún del cuerpo mismo, enfatiza García. El estudio de esta unidad espacial, significará analizar construcciones sociales, ambientales y simbólicas de enorme complejidad, ya que representarán las de la familia en su propio proceso de constitución, como el de la sociedad de la que forma parte.

La vivienda representa la dialéctica del ser social con ella misma como la materialización de él, pues plasma los supuestos de referencia sociales y culturales de ese sujeto que la edificó, representando a la vez la expresión continua, a través del tiempo y del espacio, de estas manifestaciones culturales. En este sentido, la casa cristaliza las percepciones que de la vida se posee, así como lo que se espera de ésta; todo un cúmulo de simbolismos, sueños y esperanzas, siendo por ello la posibilidad de construcción de sentido de vida. Ante esto, se puede sostener que la vivienda es el espacio con mayor significación del sujeto y donde se pueden construir las identidades personales, que contribuirán por ello a las identidades de grupo. Así como el hombre es la condensación de la sociedad y ésta es la totalidad de esas condensaciones, la vivienda es la materialización de la ciudad y ésta, la totalidad de esas cristalizaciones, por lo que no se puede entender la una sin la otra.

En esas materializaciones, los poblados también muestran una dialéctica entre las formas de vida, tradiciones culturales de la sociedad que cobijan y los aspectos ambientales donde se insertan, y como diálogo social-arquitectónico, muestran las características de ser cambiantes, pues cambiantes son los sujetos que la viven. Ahora bien, los poblados manifiestan esta sociedad en movimiento pero a la vez, y de manera significativa, continúan construyendo a ese sujeto que los vive, siendo por ello receptorestransformadores de los propios sujetos que los hacen posibles. Por ello Narváez dice que pareciera que éstos y la imaginación se mezclan en la vida de cada individuo. Es aquí la expresión continua de la condensación del todo en la parte, de tal manera que uno contiene al otro transformando a la vez por esa condición de contenedor.

Los poblados como producto de esas distintas fuerzas del hombre y del medio, pareciera que se erigieron de forma aleatoria; sin embargo, todos obedecen a un orden establecido por los propios sujetos, estén ellos conscientes de esto o no. Entonces, para sus habitantes, estos serán observados en un conjunto de imágenes construidas en la cotidianidad y por ello conformados de coherencia y lógica. Mas por esto mismo, podrán aparecer caóticos o desordenados para el sujeto temporal u observador que los visita, ya que estas personas participarán del propio sentido de orden que su cultura les otorgó. En este sentido, para entenderla será necesario comprender primero el concepto de modelo cultural-poblado que posee el sujeto, o bien, a través del estudio de estos, acceder al modelo de cultura que el individuo construyó. 
Así como la vivienda constituye la materialización de los individuos que la habitan, los poblados se convertirán en organismos espaciales de cuya interacción de todos sus habitantes emanarán sus propios valores. Por ello es que para su comprensión es menester analizar tanto la dimensión diacrónica de su constitución, como las diferentes formas de interpretación de cada observador, y las que poseen cada corriente de análisis. Esto en sí mismo es una postura de análisis particular que utiliza para la comprensión del hecho urbano-social, entre otras cosas, los mapas cognitivos que los sujetos construyen en la cotidianidad. Sin embargo, y siguiendo esta postura, la utilización de esta herramienta también reconstruye al sujeto que la construye, existiendo permanentemente una interacción conducta-mapa cognitivo. Es decir, por externalizar los significados y valores de su cotidianidad urbana, el sujeto modifica esa cotidianidad y sobre todo, la valoración que de ésta posee.

\subsection{El Patrimonio}

Como parte de un poblado o de un territorio dado, existen elementos, arquitectónicos unos, culturales otros, que sobresalen por alguna característica particular. A ellos se les ha denominado patrimonio. No obstante, pareciera que esta categorización dejaría claro lo que significa eso, pero no es así. Como ya se ha mencionado, así como cambian el hombre, los poblados y las formas de vida, también ha cambiado la forma en que se ha entendido el patrimonio, llevando consigo maneras distintas para tratarlo.

El patrimonio en sí mismo no existe como tal, sino que es un constructo social realizado para otorgarle a determinados espacios, edificios o actos culturales, un reconocimiento diferente al resto de lo construido por la sociedad o grupo social. En este sentido, Manzini dice que el patrimonio en su origen poseía un significado inicial derivado de ciertas funciones que realizaba, es decir, no se consideraba distinto al resto por ello y que a lo largo de la vida, los propios sujetos le fueron dando significaciones distintas, muchas veces contrarias a las originalmente establecidas. En este sentido, se podría decir que ha habido un cruce de distintas miradas, todas ellas surgidas en la cotidianidad del y con el elemento vivido. Entonces, hablar de patrimonio implicará considerar a la cultura que le construyó y que le da o le puede otorgar sentido por ello, o incluso que puede dejar de dárselo. Todo esto será, a juicio de Martínez Samper, pieza clave para la comprensión del mismo.

En la construcción de la categoría de patrimonio, en su inicio se tomaba sólo lo que un grupo de intelectuales o estudiosos determinaba lo que poseía valor histórico o arquitectónico para ese reconocimiento, sin embargo y a raíz del cambio de paradigma a mediados del siglo XX, este supuesto se ha modificado significativamente. Ahora las consideraciones de esos grupos para esa denominación, ponderan lo que los sujetos sociales viven o señalan en la interacción con lo construido. A esto se le ha llamado giro interpretativo. Esta nueva manera de interpretar considera el valor de lo contingente y lo particular, así como la autoridad de las tradiciones, la lectura de los edificios como textos, el simbolismo construido en la cotidianidad, entre otras cosas. Sin embargo, en la mayoría de los casos, son personas extrañas al grupo social que detenta el bien, los que le otorgan el reconocimiento de patrimonio, estando la comunidad, las más de las veces, ajena a lo que esto conlleva.

Derivado de lo anterior, de lo que se trata en la actualidad es de conceptualizar primero y reconocer después que el patrimonio participa de una dinámica propia de un grupo de personas insertas en un espacio particular; todo ello construido y simbolizado como lugar. Lugar que asimismo es perteneciente a un contexto mayor e interactuante con otros similares o afines, llamado territorio. Entonces, lo que se intenta fundamentalmente es de territorializar el patrimonio, significando con ello que éste es la expresión de esa comunidad particular que le otorga sentido precisamente porque pertenece a un suelo natal o 
patrio. En este sentido el patrimonio, aunque en el transcurso del tiempo pase a posesión privada, en su conceptualización tendrá el carácter, aunque sea parcial, de bien público.

Esas cualidades que adquiere el patrimonio por gozar de una territorialización, corresponden en cierto sentido a las cualidades propias del lugar, que son: identidad, relación e historicidad. Luego, el significado cultural de lo que se haya determinado como patrimonio, puede no estar siempre o para siempre determinado, admitiendo además que en cada época adquiera nuevos significados. En este sentido, ¿quién debe determinar lo que aún debe ser protegido como patrimonio: la comunidad que lo posee o los estudiosos que lo observan? ¿Debe ponderarse la presencia histórica y significativa de ese patrimonio para su conservación sobre la inmediatez de vida del grupo social que lo construyó? Una discusión que no tendrá respuesta sencilla ni pronta, ya que en gran parte estará determinada por la conceptualización que de patrimonio se esté construyendo.

La primera categoría utilizada para valorar un bien fue la de patrimonio arquitectónico, mostrando una obra edificada en particular que posee ciertas características dignas de conservarse: "El patrimonio arquitectónico reúne los bienes edificados con valor cultural heredados del pasado" Martínez Samper (2012:186). Tiempo después se incorpora la de patrimonio cultural para significar aquellos bienes que son expresiones y testimonios de la creación humana propios de un país. Para tener mayor claridad de algunos aspectos de esas creaciones, se incorporó la categoría de patrimonio intangible para especificar aquellas que no son factibles de cuantificarse ni materializarse, pero que por su esencia en la vida del grupo social, representan un gran significado. Todas ellas, en mayor o menor grado, significan el continuum del grupo social que las construyó, siendo por ello un encuentro entre la tradición y la modernidad.

Como se ha venido señalando, el hombre, la vida y por ello la realidad, se encuentran en movimiento, donde el espacio-tiempo es parte conformante de su institución. Pues bien, así como todo eso cambia por su propia condición, también lo que de ello emane, siendo el patrimonio una de esas formas de cambio, quizás no como objeto en sí, sino más bien como forma de percibirse; su uso, en consecuencia. El patrimonio, sea éste arquitectónico o cultural, dado que se encuentra inserto o es parte de un contexto más amplio que a la vez participa en la interacción con otros, recibe las influencias de esas otras formas de vida, por lo que el uso de éste puede modificarse o transformarse significativamente. Esto no es problema menor, puesto que en su análisis, conservación o recuperación, debe considerarse a la comunidad que lo posee o que de alguna manera tiene incidencia directa con el mismo.

Derivado de lo anterior, el patrimonio si bien refleja las presencias de un grupo o grupos sociales, también es el espacio de lucha material de sujetos con los que se vincula o de los que se es parte. Esa lucha implicará, entre otras cosas, los diferentes intereses de los actores activos u observadores que influirán a su vez, en su valoración. Es así que, incluso, si el Estado otorga esa valoración de patrimonio arquitectónico a un edificio en particular, éste puede ser defendido a costa de los propios sujetos que lo habitan o comparten. Tal es el caso, dice Guerrero, cuando el deterioro y uso inapropiado de estos espacios ya no es sancionado en relación al riesgo de sus habitantes, sino con base al daño "al patrimonio de la nación y de la humanidad", siendo que muchas de las veces, ese cambio de uso se debe precisamente al cambio natural de la forma de vida de la gente o a su bajo nivel económico, que les impide realizar cualquier acción de conservación. Éste puede ser el caso de la inmensa mayoría de los objetos, edificios o actos patrimoniales en el país, puesto que las autoridades tienen muchas reglamentaciones y poco o nulo apoyo económico a las comunidades para su conservación o recuperación. Es así que se observan edificios catalogados como patrimoniales en completo abandono, deterioro e incluso destruidos totalmente. El 
patrimonio no es precisamente el objeto como tal, sino la significación cultural e histórica, y en algunos casos arquitectónica, que éste representa, de ahí su valor.

\section{El Método}

Ahora bien, analizar el nudo onto-teleológico que se forma por la unión entre el hombre, la sociedad y el patrimonio, implicará un esfuerzo cognitivo y volitivo incluyente de un paradigma onto-epistemológico acorde a esta exigencia, pues de lo que se trata, diría Marx, no es explicar las condiciones existentes, sino transformarlas hacia otras económicamente más justas, socialmente equilibradas y espiritualmente plenas. Por ello mismo, se debe observar la investigación en tanto objeto de estudio y en tanto objeto de transformación. Lo primero para comprender el fenómeno concreto y condensado de la realidad total y lo segundo como potenciación de las condiciones existentes en la intencionalidad para su transformación. De lo que se trata en esta investigación es de plantear al hombre erguido en su historicidad, no subsumido a los medios de producción capitalista.

Para ello se recurre a una matriz desarrollada por Padrón, que denomina Matriz de Enfoques Epistemológicos, entendiendo por ella los "sistemas de convicciones preteóricos y precognitivos", los cuales "condicionan el modo en que conocemos y que implican ciertas preconcepciones sobre qué es el conocimiento y sobre cuáles son sus vías legítimas de producción y validación". De acuerdo con este autor, "el enfoque epistemológico vendría a ser una función que transforma determinadas convicciones de fondo, inobservables, de tipo ontológico y gnoseológico, en determinados estándares de trabajo científico, estándares asociables a las distintas comunidades académicas" (Padrón 2007:29), añadiendo incluso, a distintos paradigmas científicos.

Así, gnoseológicamente se reconocerían dos orientaciones posibles: empirismo y racionalismo; mientras que ontológicamente se reconocerían otras dos: idealismo y realismo. Las combinatorias posibles de estas variables y sus valores establecerían una suerte de matriz de cuatro enfoques epistemológicos básicos, que se muestran en el siguiente cuadro, en el que además se señalan sus respectivas correspondencias con algunos de los paradigmas de investigación y con los métodos de conocimiento:

\section{Cuadro 1. Matriz de Enfoques Epistemológicos}

\begin{tabular}{|c|c|c|}
\hline & \multicolumn{2}{|c|}{ Variable Gnoseológica } \\
\hline $\begin{array}{l}\text { Variable } \\
\text { Ontológica }\end{array}$ & Empirismo & Racionalismo \\
\hline Idealismo & $\begin{array}{l}\text { ENFOQUE EMPIRISTA-IDEALISTA } \\
\text { Paradigma de la Investigación Cualitativa } \\
\text { (La vivencia) } \\
\text { Inducción/abducción }\end{array}$ & $\begin{array}{l}\text { ENFOQUE RACIONALISTA-IDEALISTA } \\
\text { Paradigma de la Hermenéutica } \\
\text { (La intuición) } \\
\text { Abducción }\end{array}$ \\
\hline Realismo & $\begin{array}{l}\text { ENFOQUE EMPIRISTA-REALISTA } \\
\text { Paradigmas (Neo)positivista y } \\
\text { (Neo)conductista, Marxismo Evolucionista } \\
\text { (La observación) } \\
\text { Inducción }\end{array}$ & $\begin{array}{l}\text { ENFOQUE RACIONALISTA-REALISTA } \\
\text { Paradigma Estructuralista, Estructuralismo } \\
\text { Marxista } \\
\text { (El razonamiento) } \\
\text { Deducción }\end{array}$ \\
\hline
\end{tabular}

Fuente: adaptado de Padrón (2007). 
En esta matriz, el cruce de cada uno de los dos pares de valores correspondientes a las variables gnoseológica y ontológica, produce los cuatro enfoques epistemológicos básicos siguientes: el empiristaidealista, el empirista-realista, el racionalista-idealista y el racionalista realista, cada uno de los cuales emplea preferentemente un tipo de inferencia y se asocia con uno o más paradigmas de la ciencia. Asimismo, siempre siguiendo a Padrón, cada uno de estos cuatro enfoques desarrolla un tipo de ciencia acorde con los objetos con los que trabaja; así, el enfoque empirista-idealista trabaja con los objetos vivibles o experienciables (la vivencia); el empirista-realista con los objetos observables (la observación); el racionalista-idealista con los objetos intuibles (la intuición); y el racionalista-realista con los objetos pensables o calculables (el razonamiento).

En el caso de la arquitectura y en particular de la postura con que se aborda el objeto de estudio motivo de este artículo, los objetos vivibles refieren lo que se experimenta en y con el espacio habitable por parte de quienes lo habitan; los objetos observables refieren, por ejemplo, lo que se observa, la descripción y el análisis de conductas "objetivas" de los sujetos en el espacio habitable, o bien lo que se observa de dichos espacios físicos como unidades analíticas; en ambos casos por parte del investigador. Los objetos intuibles refieren la interpretación (lo que se dice o escribe), acerca de conductas o propiedades y características de las prácticas o de los discursos, sociales y simbólicos, alrededor de los espacios habitables; mientras que los objetos pensables (lo que se razona o calcula) refieren abstracciones teóricas o bien mediciones técnicas que el investigador elabora sobre tales espacios.

Con arreglo a la Matriz de Enfoques Epistemológicos y del discurso de un corpus historiográfico analizado por Sifuentes y Acosta, se desprenden los siguientes objetos de estudio:

Cuadro 2. Objetos de estudio subyacentes en un corpus de historiografía arquitectónica, conforme a la Matriz de Enfoques Epistemológicos

\begin{tabular}{|c|l|l|}
\hline $\begin{array}{c}\text { Variable } \\
\text { Ontológica }\end{array}$ & \multicolumn{1}{|c|}{ Variable Gnoseológica } \\
\hline \multirow{5}{*}{ Idealismo } & \begin{tabular}{l}
\multicolumn{1}{|c|}{ Empirismo } \\
Onfoque 1. Ciencia de los objetos vivibles \\
Inferencia Inductivo-Abductiva (IIA) \\
Objeto de estudio: El espacio habitado
\end{tabular} & $\begin{array}{l}\text { Racionalismo } \\
\text { Enfoque 2. Ciencia de los objetos } \\
\text { intuibles } \\
\text { Inferencia Abductiva (IA) } \\
\text { Objeto de estudio: El espacio habitable } \\
\text { representado }\end{array}$ \\
\hline Realismo & $\begin{array}{l}\text { Enfoque 3. Ciencia de los objetos } \\
\text { observables } \\
\text { Inferencia Inductiva (II) } \\
\text { Objeto de estudio: El hecho } \\
\text { arquitectónico "objetivo" }\end{array}$ & $\begin{array}{l}\text { Enfoque 4. Ciencia de los objetos } \\
\text { calculables o pensables } \\
\text { Inferencia Deductiva (ID) } \\
\text { Objeto de estudio: La arquitectura como } \\
\text { proceso de producción }\end{array}$ \\
\hline
\end{tabular}

Fuente: elaboración propia, adaptada de Padrón (2007).

Desde el enfoque empirista-idealista, el objeto privilegiado ha sido el espacio habitado, vivido o experimentado por los sujetos. Desde el enfoque empirista-realista el objeto ha sido el hecho arquitectónico como hecho histórico objetivo para el historiador. Desde el enfoque racionalista-idealista el objeto ha sido el espacio habitable tal como se lo puede representar por el habitador o interpretar por el investigador como resultado de la negociación entre sí mismo y los testimonios y vestigios del pasado. 
Desde el enfoque racionalista-realista el objeto ha sido la arquitectura producida según como la abstrae, explica (racionaliza) o mide (tecnifica) el investigador.

Dada la postura dialéctica-crítica que sustenta el objeto de estudio que actualmente se está trabajando, se hace necesaria una investigación que si bien parte del fenómeno de la apropiación del espacio desde la perspectiva emic, al incorporar variables contextuales que influyen en la propia vivencia de los habitantes (y que por tanto hacen que una situación particular necesariamente se complejice), el problema exige en consecuencia una mirada totalizante que comprenda tanto el habitar de las personas y la interpretación subjetiva de la significación de ese acto (Enfoques 1 y 2 del Cuadro 2), como el análisis objetivo aunque epifenoménico del espacio per se y del proceso estructural de la producción social misma de dicho espacio (Enfoques 3 y 4 del Cuadro 2).

Asimismo, y debido a esas características onto-gnoseológicas y teleológicas del objeto de estudio, Rapoport plantea como instrumento interpretativo para el arquitecto, los mapas mentales que los sujetos han construido de su lugar, ya que mostrarán los esquemas e imágenes mentales del mismo, no tanto las formas físicamente materializadas, que si bien también son importantes. Se trata entonces de entender qué, cómo, cuándo, quién, dónde, por qué, de la hacienda, la comunidad que la habita, en el mundo rural, y ambas en indisoluble dialéctica. Dicho de otra manera, es partir de la lógica de descubrimiento para entender los ritmos y candencias del objeto de estudio, para en el segundo momento investigativo, explicar lo concreto en un discurso potenciador. Es decir, se deben plantear dos momentos investigativos: el primero mostrando la lógica de descubrimiento y el segundo señalando la lógica de exposición; el primero como objeto de estudio y el segundo como concreto.

En ese primer momento investigativo, el objeto de estudio bajo la lógica de descubrimiento y con la intencionalidad planteada, exige cognitivamente construir el esquema de investigación, misma que será la guía cognitiva para encontrar las obras, autores y trabajo de campo (que en este caso se requiere), para analizar y encontrar los entramados categóricos-conceptuales de ese material revisado. Una vez hecho esto y con la comprensión del objeto de estudio terminado, se procede a la construcción del esquema de explicación bajo la lógica de exposición.

El esquema de explicación es significativamente diferente al esquema de investigación, porque el segundo implica la necesidad cognitiva para apropiarse del objeto y el primero la certeza de su comprensión. Este proceso investigativo desde la estructura para la dialéctica crítica, hace aparecer como si de dos objetos de estudio se trata, pues se tiene primero un esquema de investigación y posteriormente uno de explicación, cuando en el hipotético-deductivo a priori se establece cómo se va a explicar el objeto de estudio que aún no se ha investigado. Como intención fundamental del primer momento investigativo será encontrar ese entramado categórico-conceptual de los autores, mismo que permitirá construir las herramientas cognitivas e instrumentales para las observaciones y acercamientos con los actores del objeto a investigar, que para este caso, se refiere a las comunidades de estudio. En el segundo momento de la investigación por su parte, pretende construir el discurso con el entramado categórico-conceptual propio del investigador, como se ha mencionado. No se trata apoyarse de marco teórico alguno, ni de ningún marco, sino de categorías y conceptos pertenecientes a las distintas teorías que pueden estar implicadas en los distintos discursos analizados, incluso si de trabajo de campo se trata. En la observación, la indagación y la pregunta, también se encuentra una postura onto-epistemológica y teleológica, por lo que este trabajo debe analizarse tratando de encontrar esa postura que el investigador y su apoyo etnográfico, sociológico o técnico posee. 
Luego entonces, para la comprensión de objetos de estudio construidos de aspectos tanto objetivos como subjetivos, y sobre todo con percepciones de vida de sujetos existencialmente presentes en el sitio de estudio, se deberá proceder a una lectura teórica de los elementos cognitivamente implicados del mismo, a lecturas de campo con la intención de observar la particular inserción de los habitantes en el sitio, así como las narrativas de los sujetos que den cuenta de las subjetividades y afectividades de ellos en un contexto arquitectónico particular. Es decir, la complejidad del objeto de estudio obliga a replantear los métodos de investigación en la búsqueda de aquel que permita la comprensión y explicación del problema observado, ya que éste no sólo es complejo, sino cambiante, porque cambiante es la realidad misma. Por ello, no se trata de demostrar teoría alguna, sino de explicar la realidad vivida existencialmente por los sujetos de una determinada comunidad, con la intencionalidad de potenciar la condición de sujeto erguido en su historicidad.

\section{Conclusiones}

Los distintos supuestos onto-epistemológicos abordados en este trabajo e investigación como tal, permiten ser consecuentes con las necesidades de los problemas sociales actualmente encontrados. Es así que si bien se inicia con la reflexión en torno al hombre, para continuar con el espacio y el patrimonio, todos se ven interactuantes y partes del todo, aunque si bien gozando de su propia particularidad. Por ello no es posible obviar ninguno ya que la visión de la investigación es totalizante y dialéctica.

En ese sentido, se puede decir que hombre (en el sentido hegeliano) es el ser devenido y deviniente, permitiendo esto ser constructor de su historicidad. El espacio, por su parte, es el sitio que deviene en lugar al ser existencialmente vivido y habitado (en el sentido heideggeriano) por el sujeto que lo hace posible. El patrimonio arquitectónico está constituido por bienes culturalmente valorados en un momento histórico particular, pero no necesariamente concordantes con la cotidianidad de la comunidad que hace uso de los mismos.

Los objetos de estudio en general y éste en particular, al participar de una concepción totalizante y compleja, no pueden ser investigados con paradigmas fragmentarios y disciplinarios. Estos deben ser abordados desde un paradigma que dé cuenta de la propia complejidad del fenómeno de estudio y, sobre todo, de la inclusión de sujetos que viven esto como entes participantes de su propia dinámica, insertada ésta en otra como concreción. Es así que el método que se propone para llevar a buen curso esta exigencia cognitiva e investigativa, se apoya en las características de análisis del cuadro propuesto por Padrón y reelaborado por Sifuentes y Acosta, pero en el ámbito de la dialéctica-crítica como totalidad epistémica. Éste permite ser inclusivo de las distintas manifestaciones de los sujetos en su sitio de estudio, las propias referencias del investigador, así como la inserción de ambos en escenarios externos, pero influyentes del proceso investigativo.

Toda investigación, se esté consciente o no de esto, muestra la postura del investigador que la realiza. Si el planteamiento de la inquietud investigativa se encuentra basado en la realidad como devenida y deviniente, el método investigativo debe ser consecuente con ello.

Finalmente, y como sostenía Marx, no se trata de explicar el problema de estudio solamente, sino de abordarlo con la intencionalidad de transformar las condiciones existentes, observando bajo este enfoque las potencialidades subsumidas en la cotidianidad de las comunidades, pero con la fuerza identitaria de una comunidad humana construida en y por su lugar de inserción. 


\section{Bibliografía}

Ábalos, I. 2001. La buena vida. Barcelona: Gustavo Gili.

Castoriadis, C. 2005. Los dominios del hombre. Barcelona: Gedisa.

Díaz, N., Grassi, L y Mainini, C. 2011. Socialidad: los modos de apropiación del espacio público. Question (1) 29: 1-12.

http://perio.unlp.edu.ar/ojs/index.php/question/article/view/572

García, A. 2004. La casa campesina y el lugar de lo sagrado. Monterrey: UANL.

Martínez Samper, C. 2012. El hábitat de la memoria. Dedica Revista de Educaçao e Humanidades 3: 185196.

http://hum742.ugr.es/media/grupos/HUM742/cms/DEDiCA\%20N.\%C2\%BA\%203\%20IMPRESSA_.pdf

Padrón, J. 2007. Tendencias epistemológicas de la investigación científica en el siglo XXI. Cinta de Moebio 28: 1-28.

Palau, M. T. 2002. Introducción a la semiótica de la arquitectura. San Luis Potosí: Universidad Autónoma de San Luis Potosí.

Íñiguez, L. y Pol, E. 1996. Cognición, representación y apropiación del espacio. Barcelona: Publicacions Universitat de Barcelona.

Salazar, G. 2011. Lecturas del espacio habitable. San Luís Potosí: Universidad Autónoma de San Luis Potosí.

Recibo el 14 Ene 2014

Aceptado el 27 Jul 2014 